\title{
QUÍMICA DE MATERIAIS EM 25 ANOS DE SBQ
}

\section{Adley Forti Rubira}

Departamento de Química, Universidade Estadual de Maringá, Avenida Colombo, 5790, 87020-900 Maringá - PR

Aldo José Gorgatti Zarbin

Departamento de Química, Universidade Federal do Paraná, CP 19081, 81531-990 Curitiba - PR

Fernando Galembeck e Oswaldo Luiz Alves

Instituto de Química, Universidade de Campinas, CP 6154, 13083-970 Campinas - SP

Miguel Jafelicci Júnior*

Instituto de Química, Universidade Estadual Paulista, CP 355, 14801-970 Araraquara - SP

\begin{abstract}
MATERIALS CHEMISTRY IN 25 YEARS OF BRAZILIAN CHEMICAL SOCIETY. Communications on Chemistry of Materials topics were already presented in the first annual meetings of the Brazilian Chemical Society, dispersed throughout various meeting sections. The SBQ Materials Chemistry division was organized in 1993, attracting those members with an interest in the composition, structure and properties of materials, as related to their functions. This paper is an account of the development of Materials Chemistry research in Brazil, based on the SBQ annual meetings data.
\end{abstract}

Keywords: Chemistry; Brazilian Chemical Society; SBQ; Materials Chemistry.

\section{INTRODUÇÃO}

Em 1993, a Reunião Anual da Sociedade Brasileira de Química (RASBQ) apresentou a primeira sessão de Química de Materiais programada pela Divisão de Química de Materiais (DQM). A característica intrinsecamente interdisciplinar dos temas de Materiais induziu a criação da Divisão de Química de Materiais para congregar os químicos orgânicos, inorgânicos, físico-químicos, físicos, engenheiros de materiais, dentre os profissionais ligados aos departamentos universitários, institutos de pesquisas e departamentos de pesquisa e desenvolvimento de indústrias. Assim, muitos membros das outras divisões associaram-se a esta nova Divisão formando um novo foro de divulgação e discussão das pesquisas sobre materiais.

Os pesquisadores que hoje se reunem na divisão atuam nas seguintes áreas: polímeros dielétricos, estruturais ou condutores, materiais cerâmicos e vidros, materiais fotônicos, filmes finos, blendas e compósitos, fibras, elastômeros e borracha natural, dentre outros assuntos, abordando sua preparação, caracterização, propriedades, simulação, etc. Desde a criação, a Divisão de Química de Materiais tem mantido intensa programação na Reunião Anual da Sociedade organizando a apresentação de contribuições científicas na forma de comunicações orais e de painéis, mini-conferências e conferências plenárias convidadas, oferecendo cursos sobre preparação, técnicas instrumentais de caracterização e metrologia química aplicada aos materiais. A partir de 1995, a Divisão vem outorgando prêmios aos melhores trabalhos apresentados na Reunião Anual, como forma de incentivo e reconhecimento da atividade e qualidade dos diferentes grupos de pesquisa ou pesquisadores individuais. A Comissão Julgadora para a outorga dos prêmios é composta pela Diretoria da Divisão, além de quatro outros pesquisadores convidados. Nas Reuniões Anuais, é realizada a Assembléia Divisional Ordinária, fórum de decisão da Divisão, na qual são tratados os temas gerais e específicos da comunidade científica, feitas deliberações relativas às atividades da Divisão e são apresentados os Relatórios da Diretoria.

Após quatro reuniões anuais, em 1998, foi traçado o perfil da Química dos Materiais no Brasil através das reuniões da Divisão

*e-mail: jafeli@iq.unesp.br buscando-se identificar os membros da divisão, as áreas de atuação contempladas, a participação dos alunos de pós-graduação e de iniciação científica, assim como as técnicas instrumentais mais usadas no desenvolvimento das pesquisas. Os resultados das atividades iniciais da Divisão permitiram a avaliação prospectiva da área considerando os seguintes aspectos das reuniões anuais: distribuição regional dos trabalhos; distribuição e tendências dos temas de pesquisa; qualificação dos participantes; técnicas de caracterização mais utilizadas, entre outros. Os membros desta Divisão têm uma intensa atividade de publicação em diversos periódicos, e participam ativamente de outras reuniões da área de Materiais no país e no exterior.

\section{RELEVÂNCIA DA QUÍMICA DE MATERIAIS}

Para, atualmente, entendermos a relevância da Química de Materiais, bem como seu papel no conjunto das chamadas Ciências dos Materiais, algumas considerações preliminares se fazem necessárias. No início do século passado, século XX, portanto, praticamente a grande maioria das tecnologias era dominada pelos materiais metálicos, cerâmicos e de origem vegetal. Todas as atividades, então, caracterizavam-se por um traço comum: eram fundadas em fontes nãorenováveis implicando, assim, em um elevado consumo de insumos energéticos. Dado ao grande desenvolvimento ocorrido nesse século - marcado por forte interação de novas idéias e conceitos científicos - houve uma progressiva substituição de materiais escassos, caros ou estratégicos, o que acabou por viabilizar novas tecnologias, tornadas possíveis graças aos inúmeros materiais recém-descobertos.

Não resta a menor dúvida de que as atividades humanas do fim do século XX e início deste milênio foram e estarão fortemente marcadas pela criação, aperfeiçoamento e disseminação dos materiais. Certamente não existiria a microinformática sem a microeletrônica, esta baseada no silício. Seria impensável o automóvel contemporâneo, de alta segurança e elevado rendimento energético sem os plásticos, aços de alto desempenho e as atuais pinturas automobilísticas, para ficarmos apenas nesses exemplos. Tal situação coloca-nos frente a um novo paradigma, ou seja: esta não é a idade de um único material (como se costumava caracterizar outros períodos da história da humanidade), mas sim a idade do uso múltiplo, 
amplo, inteligente (muitas vezes) e diversificado de um grande número de materiais, adequados a muitas e importantes funções. É também a época de descoberta de outras muitas e novas funções, antes inexistentes, cujas possibilidades são percebidas pelos que estudam os materiais récem-descobertos, ou avaliam novas possibilidades da integração conjugada de propriedades daqueles já conhecidos. A idéia de complexidade junta-se a estes novos paradigmas, contribuindo para a antevisão e compreensão das estruturas que podem ser geradas pela interação e a integração de diferentes materiais.

Tais fatos foram fortemente sentidos a partir de 1981, quando se observaram dois movimentos, a um só tempo importantes e distintos, no contexto internacional da Química. O primeiro, ligado a um vertiginoso desenvolvimento e aplicação de novas técnicas de análises espectroscópicas, microscópicas, térmicas, mecânicas e eletroquímicas; o segundo, iniciado na década de 70, com o surgimento de uma nova disciplina química: a Química de Materiais, fortemente impulsionada pela expansão das fronteiras científicas e pelas necessidades do desenvolvimento tecnológico. Nessa mesma época passou-se a utilizar a expressão novos materiais (hoje quase em desuso na literatura), para designar substâncias, compostos e sistemas que apresentavam novas e importantes propriedades condutoras, ópticas, magnéticas, catalíticas, de separação química, etc ${ }^{2}$.

O estabelecimento da identidade da Química de Materiais se deu, também, graças a alguns movimentos editoriais. Em meados de 1987, a revista Angewandte Chemie (uma das revistas de Química de maior índice de impacto), editada pela $\mathrm{VCH}$, fez veicular em seus números um encarte com o título Advanced Materials, que logo daria origem a uma nova revista, basicamente de Química de Materiais. O mesmo ocorreu com a Royal Chemical Society e American Chemical Society que, respectivamente, lançaram os periódicos: Journal of Materials Chemistry e Chemistry of Materials. Tais revistas figuram hoje entre as mais importantes publicações das respectivas sociedades científicas ${ }^{2}$.

A Química de Materiais tratando da síntese, estrutura, propriedades e aplicações dos materiais, sobretudo daqueles associados com o avanço de diferentes tecnologias, tem tido contínuo e enorme sucesso, na medida em que coloca em destaque o conhecimento, o saber e o fazer químicos, como no caso dos polímeros sintéticos e dos materiais inorgânicos, obtidos por rotas eminentemente químicas. Esses aspectos explicitam a Química de Materiais como uma das principais fronteiras da Química e, especialmente, como uma atividade relevante, que produz vantagens diferenciais e competitivas a favor do desenvolvimento crescente de uma indústria nacional, de forte base tecnológica.

\section{MATERIAIS POLIMÉRICOS}

A atividade em materiais poliméricos apresentou uma evolução qualitativa e quantitativa muito acentuada, nos 25 anos de existência da SBQ. Um levantamento apresentado em $1982^{3}$ evidenciava três características: i) poucos centros atuando nesta área; ii) poucas publicações na literatura internacional, evidenciando uma pequena produção científica e iii) pouca interação entre pesquisadores acadêmicos e de empresas, restrita a projetos de curto alcance. Os centros que então tinham produção científica detectável eram apenas os da UFRJ, UFSCar e Unicamp, além da UFRGS que tinha então um programa de formação de doutores na Universidade de Freiburg, na Alemanha.

A situação em 2002 é radicalmente diferente, como está ilustrado na Tabela 1. Esta apresenta grupos identificados através do Banco de Dados de Currículos Lattes ${ }^{4}$, usando as palavras-chaves que estão na primeira coluna da Tabela. Na segunda coluna estão listadas as instituições às quais estão afiliados grupos identificados como pertencentes à área de Química, e na terceira coluna estão as instituições a que pertencem grupos de áreas afins que também atuam em polímeros.

Portanto, a atividade em materiais poliméricos é hoje muito descentralizada, sendo praticada em várias institutições, em diversos estados do país. Também é multidisciplinar, de maneira que outros eventos importantes competem com a RASBQ na condição de fóruns para a apresentação de trabalhos sobre polímeros, no país: os principais são os congressos da ABPol, da SBF, o CBECIMAT e a reunião da SBPMat.

Existe uma atividade de pesquisa intensa e diversificada na maioria dos tópicos importantes da área: síntese, caracterização, propriedades, blendas e compósitos, degradação e estabilização, polímeros condutores. É possível observar que, mesmo em alguns tópicos tradicionais, só surgiu produção científica de expressão internacional recentemente, como está mostrado na Tabela 2.

Os temas de pesquisa são atuais, e a maioria dos trabalhos apresentados nas RASBQs chega à literatura internacional. Uma parte significativa dos grupos atua nos temas mais ligado às novas tecnologias, como os polímeros condutores e sistemas eletrocrômicos, mas também há atividade importante em áreas mais maduras embora dinâmicas, como elastômeros e látex, entre outras. Dados numéricos ilustrativos estão adiante na Tabela 5 .

$\mathrm{Na}$ última década houve uma verdadeira explosão da produção científica brasileira na Química de Materiais ${ }^{5}$ e em áreas correlatas, que pode ser evidenciada da seguinte forma: buscando no "Web of Science" o número de artigos, em todos os anos de cobertura (de 1945 até o presente), e usando as palavras de busca "polymer or plastic or rubber or latex or composite or blend" junto ao indicador de endereço "Brazill", são recuperados 3029 títulos; destes, a metade data de 1998, ou de ano posterior. Portanto, a metade das publicações brasileiras no "Web of Science" data dos últimos quatro anos, e a outra metade data dos 25 anos anteriores. O mesmo procedimento pode ser aplicado a outras palavras-chaves, e o resultado é claro: nos últimos três ou quatro anos foram publicados trabalhos que repre-

Tabela 1. Instituições nas quais existem grupos de pesquisa em temas de Polímeros. As instituições nas quais há grupos da área de Química e de grupos de outras áreas (Engenharia, Física) estão em colunas separadas

\begin{tabular}{|c|c|c|}
\hline Tema & Instituições que têm grupos na área de Química & Instituições que têm grupos nas áreas de Engenharias e Física \\
\hline Compósitos poliméricos & Unicamp, UFRJ, UFSCar, UEM & $\begin{array}{l}\text { UFSCar, UFRJ, UFPR, UFMT, Embrapa, UFPB, UFRRJ, IME, } \\
\text { Unicamp }\end{array}$ \\
\hline Materiais poliméricos & $\begin{array}{l}\text { EFEI, Faenquil, UEM, UERJ, UFRJ, CNEN, } \\
\text { UFOP, UFRN, UnB, UFPE, UFSC, UFRGS, } \\
\text { UFMG, Unicamp, USF }\end{array}$ & $\begin{array}{l}\text { UFSCar, CEFET/PR, CNEN, ITA, UNISC, PUC/RJ, PUC/RS, } \\
\text { PUC/PR, UNESP, UFRGS, USP, UFPB, UENF, UERJ, UFRRJ }\end{array}$ \\
\hline Química de polímeros & $\begin{array}{l}\text { UCB-DF, UnB, UFRJ, UFBA, UFRGS, UFC, } \\
\text { UFRN, UERN, Unicamp, UFPel, UA, USP, } \\
\text { USP-SC }\end{array}$ & Unicamp, UFRJ \\
\hline
\end{tabular}


sentam a metade do total indexado em todos os anos, nos mesmos tópicos.

A Tabela 2 mostra que a contribuição brasileira à literatura internacional excede a média nacional, em vários tópicos, como: "metallocene polymerization, styrene and latex, conduct polymer". Há também um volume de trabalho significativo sobre materiais naturais, sejam fibras, elastômeros ou polieletrólitos. Entretanto, não há ainda sinais significativos de alguns outros novos paradigmas da Química (síntese combinatória, uso de tecnologias genômicas) nesta área.

Os relatos metodológicos das comunicações apresentadas às RASBQs permitem concluir que os pesquisadores têm acesso a instrumentação atualizada e bastante diversificada, com uma razoável disponibilidade de equipamentos em muitos laboratórios, mas com uma óbvia concentração na região sudeste e especialmente em São Paulo. Todas as técnicas importantes podem ser praticadas em diferentes partes do país, com a exceção das técnicas de espalhamento ou refletividade de nêutrons, para as quais não existe nenhuma facilidade. Entretanto, existe uma oferta de tempo para uso de facilidades deste tipo em vários laboratórios de países desenvolvidos, de maneira que esta não é uma limitação importante para pesquisadores brasileiros.

\section{MATERIAIS NÃO-POLIMÉRICOS}

Da mesma maneira como se deu com os materiais poliméricos, as atividades levadas a cabo envolvendo materiais não-poliméricos apresentaram uma evolução não só qualitativa, mas também quantitativa, ao chegarmos aos 25 anos da Sociedade Brasileira de Química. Não obstante grande parte diga respeito a uma história mais recente, há que se considerar que parte significativa da atividade que se realiza atualmente, teve sua origem em duas importantes e bem focalizadas iniciativas. A primeira, ligada ao Grupo de Coordenação em Química de Sólidos (82-86), patrocinado pelo CNPq, que realizou uma série de reuniões e "workshops" pelo Brasil, aproximando a comunidade que, àquela altura, se lançava no estudo de sólidos, sobretudo os inorgânicos. A segunda, mais com característica de programa, financiada pela Finep (86-91), denominada Programa Na- cional de Química para Materiais Eletrônicos - PQME, que teve sua sede no Instituto de Química da UNICAMP.

Os dois programas tiveram o mérito intrínseco de reunir pesquisadores intereressados na temática de materiais como um todo, com uma parcela considerável relacionada a materiais não-poliméricos (inorgânicos). À epóca, as temáticas desenvolvidas nos institutos de química iam dos óxidos magnéticos aos materiais bidimensionais (lamelares), passando por sistemais coloidais inorgânicos, cerâmicas e vitrocerâmicas. As instituições envolvidas eram bem poucas, ainda, destacando-se o antigo Instituto de Física e Química da USPSão Carlos (hoje Instituto de Química de São Carlos), o Instituto de Química da Unicamp, o Departamento de Química Fundamental da UFPE e o Instituto de Química de Araraquara, da UNESP.

A avaliação que se pode hoje fazer desse início ressalta: i) poucos institutos aparelhados para trabalhar com Química de Materiais, sobretudo aquela ligada a sólidos, dado ao fato de que a vocação por eles experimentada até aquele momento passava pela química de soluções ou de natureza totalmente molecular. Difratômetros de raios-X e microscópios eletrônicos eram uma raridade; ii) quase total ausência de cultura, bibliografia e cursos de Química de Estado Sólido e de Materiais, o que dificultou sobremaneira atrair estudantes para a área; iii) pequena produção científica nacional e, sobretudo, internacional, o que impedia dar visibilidade a área, levando a uma interação quase nula com o setor produtivo que, a essa altura, somente demandava por testes e análises.

Durante a década de 90, o quadro foi se modificando gradualmente e, a partir da fundação da Divisão de Química de Materiais, da SBQ, foi possível organizar as atividades dando à Química de Materiais um novo dinamismo, como já observado na Introdução. Podiam ser identificados grupos e laboratórios trabalhando com vidros especiais, processo sol-gel, cerâmicas eletrônicas, óxidos semicondutores, zeólitos, filmes, compósitos organo/inorgânicos, entre outros, e, mais recentemente, com sistemas nanoparticulados, quantum-dots, novas formas de carbono, etc, estes últimos já como contribuição da Química para as chamadas Nanociências.

No que diz respeito às instituições que têm atividades em Química de Materiais, o ano 2002 apresenta já um quadro totalmente diferente dos idos 80. Apesar dos grupos estarem em diferentes está-

Tabela 2. Número de referências listadas no "Web of Science", relativas a algumas palavras-chaves ou conjuntos de palavras-chave

\begin{tabular}{|c|c|c|c|c|}
\hline $\begin{array}{l}\text { Palavra-chave ou conjunto } \\
\text { de palavras-chave }\end{array}$ & $\begin{array}{l}\text { Número de } \\
\text { ocorrências (n), } \\
\text { associadas } \\
\text { ao Brasil }\end{array}$ & $\begin{array}{c}\text { Número } \\
\text { global de } \\
\text { ocorrências }(\mathrm{m})\end{array}$ & $\begin{array}{l}\text { Ano da primeira } \\
\text { ocorrência associada } \\
\text { ao Brasil }(n=1) \text { e } \\
\text { (ano da referência } \\
\text { brasileira mediana) }\end{array}$ & $\begin{array}{c}\text { Ano da primeira } \\
\text { ocorrência global } \\
(\mathrm{m}=1) \text { e (ano da } \\
\text { referência global } \\
\text { mediana) }\end{array}$ \\
\hline
\end{tabular}

\footnotetext{
"polymer or plastic or rubber

or latex or composite or blend"

"biodegradable polymer"

"polymer surface"

"surface modification"

"emulsion polymerization"

"polymerization"

"plastic recycl or polymer recycl

or rubber recycl"

"conduct polymer"

"natural fiber"

"natural rubber or natural latex"

"elastomer"

"living polymerization"

"metallocene polymerization"

"styrene and latex"
}

$\begin{array}{cc}3059 & \\ 3 & 746 \\ 24 & 3033 \\ 22 & 5374 \\ 28 & 2993 \\ 624 & 79538 \\ & \\ 2 & 149 \\ 83 & 3492 \\ 5 & 128 \\ 43 & 3211 \\ 55 & 4014 \\ 2 & 1356 \\ 40 & 1917 \\ 22 & 1060\end{array}$

1973 (1998)

1999

1994

1977

1991

1978 (1999)

2000
$989(1999)$
$991(1999)$
$985(1998)$
$983(1999)$
1993
$995(2001)$
$993(1999)$

1961(1996)

1973(1997)

1947(1994)

1965(1998)

1985(1999)

1952(1997) 
gios de consolidação, têm-se grupos trabalhando com materiais em praticamente todos os institutos de química do país. Tais grupos foram formados por ex-integrantes dos grupos iniciais que capacitaram-se obtendo seu doutoramento, como também de doutores brasileiros que completaram seus estudos (doutorado ou pós-doutorado) em universidades do exterior, especialmente na França, Inglaterra e Alemanha.

A Tabela 3, obtida da consulta dos Grupos de Pesquisa do $\mathrm{CNPq}^{4}$, procura dar um panorama dessa situação. Nela são apresentadas as instituições que têm grupos na área de Química e outras instituições envolvendo as áreas de Física, Engenharias, etc.

As publicações na área de materiais não-poliméricos acompanharam o grande aumento das publicações, verificadas globalmente para a ciência brasileira, na década de 90 . A título de exemplo, na Tabela 4 pode-se verificar que, para diferentes palavras-chave, relacionadas com a sub-área, computadas do Web of Science, a maioria das publicações começaram a aparecer nos anos 90 . Somente as áreas de vidros, cerâmicas, semicondutores, óxidos e sílica figuram já nos anos setenta. É importante destacar que, nas áreas mencionadas, mais da metade das publicações foram feitas nos últimos cinco anos.

É importante caracterizar a atividade relacionada com o estudo de filmes. Do valor apresentado, mais de $45 \%$ corresponde a filmes envolvendo materiais não-poliméricos. Outro dado importante é o aumento da atividade envolvendo sistemas nanoscópicos, uma vez que mais da metade das publicações foram realizadas nos três últimos anos.

Os indicadores mostram que a pesquisa ligada aos materiais nãopoliméricos apresenta grande contribuição da Química, a qual tem aportado soluções não só para novas rotas de síntese, mas também para toda uma cultura de trabalho de forma concertada, com diferentes métodos de caracterização, sejam eles espectroscópicos, eletroquímicos, térmicos ou analíticos.

Em nossa avaliação, tal atividade tende a crescer, sobretudo porque já existe em vários pontos do país não só infra-estrutura adequada à realização dos estudos, como também grande interesse por par- te dos jovens estudantes. Além disso, facilidades como o Laboratório Nacional de Luz Síncrotron podem permitir ampliação dos estudos de aspectos estruturais e das propriedades, trazendo informações que possibilitam colocar os materiais bem mais próximos de sua efetiva aplicação.

Tabela 4. Número de referências listadas no "Web of Science", relativas a algumas palavras-chave ou conjuntos de palavras-chave

\begin{tabular}{lcc}
\hline $\begin{array}{l}\text { Palavra-chave ou } \\
\text { conjunto de } \\
\text { palavra-chaves }\end{array}$ & $\begin{array}{c}\text { Número de } \\
\text { ocorrências (n) } \\
\text { associadas ao Brasil }\end{array}$ & $\begin{array}{c}\text { Ano da primeira } \\
\text { ocorrência } \\
\text { associada ao Brasil }\end{array}$ \\
\hline "semiconductors" & 663 & 1973 \\
"oxides" & 518 & 1973 \\
"silica" & 838 & 1973 \\
"ceramics" & 299 & 1975 \\
"glasses" & 543 & 1977 \\
"superconductors" (*) & 281 & 1979 \\
"glass-ceramics" & 17 & 1985 \\
"intercalation compounds" & 28 & 1985 \\
"bioceramics" & 47 & 1987 \\
"sol-gel" & 284 & 1988 \\
"quantum-dots" & 46 & 1991 \\
"colloids" & 50 & 1992 \\
"nanotubes" & 52 & 1993 \\
"nanoparticles" & 120 & 1993 \\
"nanocrystals" & 47 & 1993 \\
"nybrid materials" & 32 & 1995 \\
"nilms" & 2179 & 1996 \\
"nanocomposites" & 51 & 1996 \\
\hline
\end{tabular}

${ }^{(*)}$ Estes dados contemplam as ligas metálicas e as cerâmicas supercondutoras.

Tabela 3. Instituições nas quais existem grupos de pesquisa em temas de Materiais Não-Poliméricos (Inorgânicos). As instituições nas quais há grupos da área de Química e de outras áreas (Engenharia, Física e outras) são apresentadas em colunas separadas

\begin{tabular}{|c|c|c|}
\hline Tema & $\begin{array}{l}\text { Instituições que têm grupos } \\
\text { na área de Química }\end{array}$ & $\begin{array}{l}\text { Instituições que têm grupos } \\
\text { nas áreas de Engenharias, Física e outras }\end{array}$ \\
\hline Materiais Usuais $^{(*)}$ & $\begin{array}{c}\text { UFRGS,UFSC,UFPR,UEL,UEM, } \\
\text { USP,Unicamp,UFSCar,UNESP,UFRJ, } \\
\text { UFMG,UFBA,UFPE,UFRN,UFC, } \\
\text { UFG,UFMS }\end{array}$ & $\begin{array}{l}\text { Praticamente em todos os Institutos de Física } \\
\text { e Faculdades de Engenharia do país }\end{array}$ \\
\hline Vidros Cerâmicas & $\begin{array}{c}\text { Unicamp,UFSCar,UNESP, } \\
\text { UFPE,UFMG,CNEN,UNB,UFES,UFG }\end{array}$ & $\begin{array}{l}\text { USP,CETEM,UFRJ,PUC/RJ,ITAL,LNLS,UFPE, } \\
\text { UFBA,UEPG,UFRGS,CNEN,UEM,UFC,UFMS, } \\
\text { TECPAR,UFJF,Unicamp,UFSCar,UFU,UERJ, } \\
\text { UFPB,UNESP,CEFET/PR,UFRJ,ITA,INPE,UEL, } \\
\text { Faenquil,UNIVALI,UERJ,UERJ,CBPF,UFES,CTA, } \\
\text { UFPR,CETEC,UENF,UNITAU }\end{array}$ \\
\hline Processo Sol-Gel & $\begin{array}{l}\text { INPE,UFRGS,CNEN,UNESP, } \\
\text { UFPE,UFPR,UFMG,Unicamp, UFG, } \\
\text { UFPB,UNIFRAN,USP-SC,USP-RB, }\end{array}$ & $\begin{array}{l}\text { UFPB,UFRJ,ITA,USP,UNESP,USP-SC,UFMS, } \\
\text { USP-RB,UFRGS,UFOP,UFMG,Faenquil }\end{array}$ \\
\hline Filmes & $\begin{array}{l}\text { CNEN,UFC,USP-SP,UFRN,Unicamp, } \\
\text { UFSCar,UNESP,USP-RP,UNIP,UFES }\end{array}$ & $\begin{array}{l}\text { UFF,UFBA,Unicamp,ITA,CBPF,USP,UNESP, } \\
\text { USF,INPE,PUC/RJ,INPE,LNLS,UFMG,UFRGS, } \\
\text { UFPR,UEL,UFSC,PUC/RS }\end{array}$ \\
\hline Compósitos Nanocompósitos & $\begin{array}{c}\text { UFPE,UFG,UNESP,UFPR, } \\
\text { Unicamp,UFRJ }\end{array}$ & UFMG,UFSCar,USP-SP \\
\hline
\end{tabular}

\footnotetext{
${ }^{(*)}$ Vide a definição dessa classe de materiais na Ref. 1
} 


\section{A QUÍMICA DE MATERIAIS NAS REUNIÕES ANUAIS DE 1993 A 2002}

A participação dos pesquisadores em Química de Materiais está representada na Figura 1 pelo número de trabalhos apresentados nas RAs de 1993 a 2002. Em 1993, quando ocorreu a primeira reunião da DQM, 5\% dos trabalhos foram da área de Química de Materiais. Até 1998, há um aumento mais acentuado do número de trabalhos devido à abertura de novos programas de Pós-Graduação com linhas de pesquisa em Química de Materiais, e o deslocamento de pesquisadores provenientes de outras áreas da Química para a DQM. A partir de 1998, o número de trabalhos apresentados se estabiliza na média de 160, sendo atingido 196 na $25^{a}$ RASBQ. Os anos em se observa diminuição na participação da DQM são anos de realização de outros eventos importantes em Materiais, principalmente o CEBCIMAT e o Congresso da ABPol. A contribuição da DQM tem se mantido nos últimos quatro anos em torno de $10 \%$ do total de trabalhos das RAs, comparando-se em 2002 com as outras áreas mais tradicionais da Química: DQO (11,0\%), DQI (8,6\%), DQA (12,3\%) e DPN $(14,1 \%)$. No decorrer de nove anos a DQM superou os índices anuais de participação mostrando significativa qualidade e quantidade da produção científica na área.

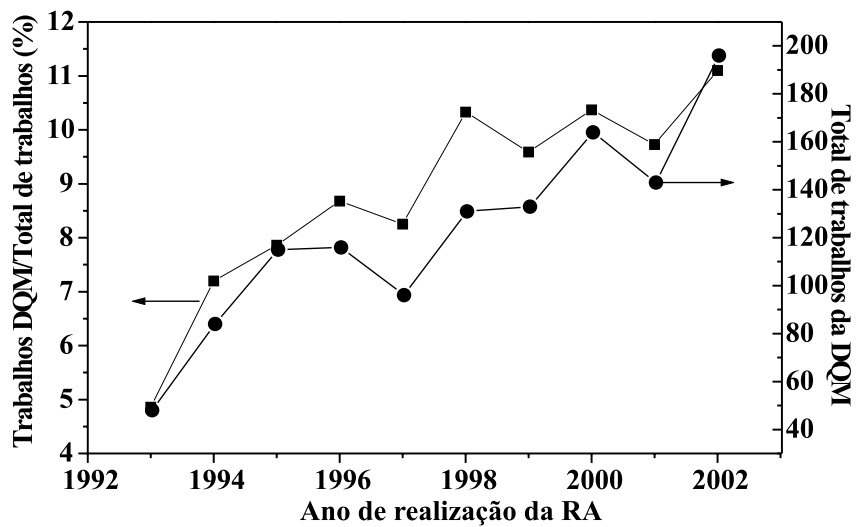

Figura 1. Evolução do número de trabalhos $(\mathbf{O})$ e da percentagem $(\mathbf{\square})$ correspondente em relação ao total de trabalhos da DQM

Os percentuais de participação das diferentes regiões do Brasil nas RAs de 1993 a 2002 estão mostrados na Figura 2. A região sudeste lidera o número de participações com a média de 72 trabalhos seguida pelas regiões sul com 17, nordeste com 15 e norte e centro-oeste. Os resultados indicam que, embora a participação das diferentes regiões venha melhorando, ainda há que se implementar políticas científicas de incentivo para o desenvolvimento regional. Considere-se ainda que a Química de Materiais é ampla e pode alavancar o Produto Interno Bruto regional através de parcerias universidade-empresa para a incubação de pequenas empresas de produtos de alto valor agregado e processos de tecnologia avançada. Diferentes setores econômicos podem se beneficiar, principalmente, os setores relacionados com materiais avançados. Cerca de $80 \%$ das contribuições da região sudeste provem do Estado de São Paulo e a parte mais significativa dessa participação é dos grupos localizados no interior do estado: Campinas, São Carlos e Araraquara. Os programas de pós-graduação incentivam o crescimento e a produção científica dos Grupos de Pesquisa com líderes formados em outros centros e nos da própria região. Destacase ainda a interação de pesquisadores com formações diferentes integrando a Química, a Física e a Engenharia, o que é essencial para integrar as diferentes contribuições necessárias.

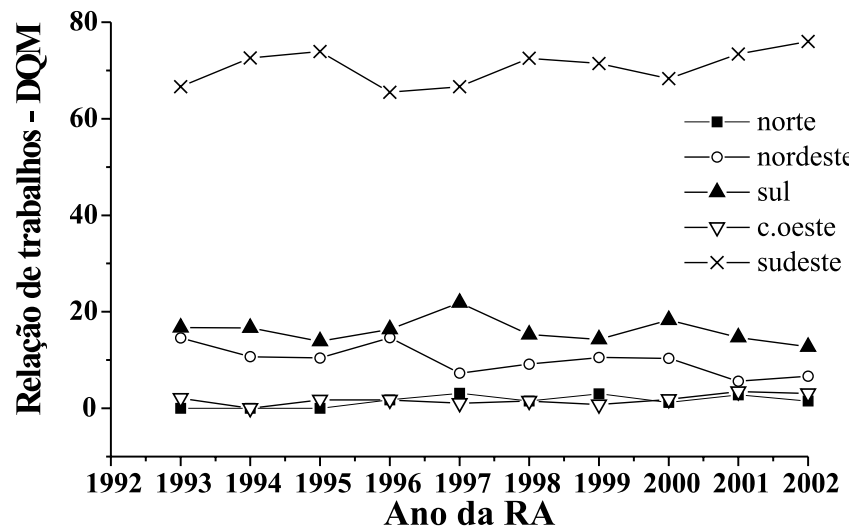

Figura 2. Participação regional - trabalhos apresentados na DQM

\section{TEMAS DE PESQUISA}

Os temas de pesquisa abordados nas RAs foram divididos arbitrariamente em duas grandes seções, de acordo com a temática utilizada no estudo da Ref. 1: materiais poliméricos e materiais nãopoliméricos. Os trabalhos foram agrupados dentro das classes apresentadas na Tabela 5.

Tabela 5. Classificação dos temas de trabalhos apresentados nas sessões de Química de Materiais e número de trabalhos apresentados de 1999 a 2002

\begin{tabular}{lcccc}
\hline \multicolumn{1}{c}{ Ano } & 1999 & 2000 & 2001 & 2002 \\
\hline Trabalhos da sessão de QM & 133 & 155 & 141 & 196 \\
\hline Temas & & & & \\
\hline Não-Poliméricos & 81 & 106 & 83 & 137 \\
\hline Materiais usuais & 8 & 50 & 28 & 26 \\
Vidros e cerâmicas & 23 & 13 & 14 & 36 \\
Sol-gel & 9 & 0 & 7 & 13 \\
Materiais não-convencionais & 23 & 9 & 15 & 44 \\
Filmes & 5 & 5 & 6 & 13 \\
Compósitos inorgânico/orgânico & 13 & 17 & 13 & 5 \\
\hline Políméricos & 52 & 49 & 58 & 59 \\
\hline Síntese e caracterização & 18 & 15 & 16 & 18 \\
Blendas/híbridos/compósitos & 11 & 14 & 21 & 16 \\
Degradação/estabilização & 8 & 8 & 5 & 4 \\
Borracha/elastômeros/termoplásticos & 0 & 6 & 3 & 8 \\
Polímeros condutores & 15 & 6 & 13 & 13 \\
\hline
\end{tabular}

A atividade de pesquisa em materiais poliméricos é dominada pelas três classes: síntese e caracterização, blendas, compósitos e híbridos e polímeros condutores. Houve um decréscimo acentuado das atividades em degradação e estabilização de polímeros. A pesquisa com materiais baseados em borracha natural e elastômeros readquirtiu importância nas RAs, a partir de 2000.

Quanto ao conjunto dos materiais não-poliméricos, os resultados indicados na Tabela 5 revelam a predominância dessa temática a partir de 1999, saltando de 53 em 1997 para 137 trabalhos em 2002.

Dentre as pesquisas sobre materiais não-poliméricos, os temas com maior contribuição foram os materiais usuais, crescendo nos dois últimos anos os trabalhos sobre vidros e cerâmicas, materiais não-convencionais e filmes. Dois fatos previstos anteriormente ${ }^{1}$, en- 
tretanto, merecem ser destacados. Primeiramente, a concretização da tendência de crescimento de vidros e cerâmicas. O segundo fato importante é o crescimento da área de filmes de materiais inorgânicos, que era inexistente até o ano de 1996.

\section{INDICADORES GERAIS DAS REUNIÕES ANUAIS}

A análise mais abrangente das reuniões desde 1993 revela o perfil e a trajetória dos nove anos de existência da DQM. Os dados foram coletados diretamente dos livros de resumos das RASBQ. Em nove anos de atividade da DQM, os resultados obtidos servem para análise e como fonte de informação sobre a Química de Materiais dentro da Sociedade Brasileira de Química e também para posterior comparação com trabalhos apresentados em outros eventos. Em todos os gráficos e tabelas considerou-se o conjunto de trabalhos apresentados em cada ano.

\section{Autoria dos trabalhos}

A autoria dos trabalhos deve-se à participação de pesquisadores líderes (PQ) dos diferentes Grupos de Pesquisa, à contribuição dos

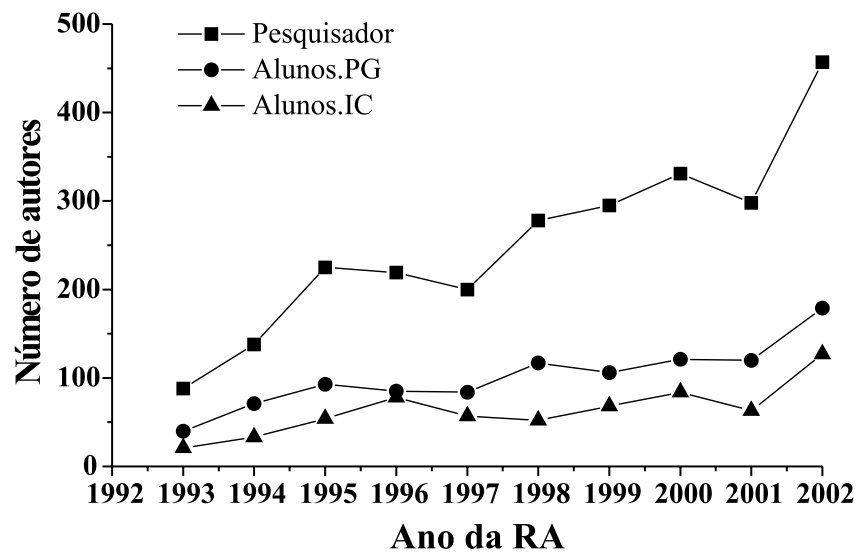

Figura 3. Número de pesquisadores (PQ), de pós-graduandos $(P G)$ e de graduandos (IC) autores de trabalhos apresentados na DQM pós-graduandos (PG) nos níveis de mestrado e de doutorado, e dos alunos graduandos, em nível de iniciação científica (IC). A Figura 3 indica o perfil em porcentagem por classe de autores em função do ano da RA. O número e a respectiva porcentagem de autores pesquisadores (PQ), pós-graduandos (PG) e alunos de iniciação científica (IC) estão na Tabela 6. Pode-se constatar que os estudantes de pósgraduação (PG) constituem $25 \%$ e os graduandos de IC, em $15 \%$ do número de autores dos trabalhos.

Na maioria dos trabalhos apresentados, os dados indicam a participação conjunta de estudantes de PG e IC, conforme constatado anteriormente ${ }^{1}$. Este resultado demonstra também que as equipes de pesquisa são constituídas por autores de diferentes níveis da atividade acadêmica. Os pós-doutores, récem-doutores e jovens-pesquisadores são classificados como pesquisadores pelas comissões organizadoras das RAs da SBQ, assim como pelo CNPq.

\section{Colaboração inter-institucional}

Os dados da Tabela 7 revelam o nível da interação interinstitucional. A maioria dos trabalhos é fruto de pesquisas realizadas em uma única instituição, permanecendo em média no valor de $70 \%$ do total de trabalhos apresentados no decorrer de todas as reuniões realizadas até o ano de 2002.

Tabela 6. Autores pesquisadores (PQ), pós-graduandos (PG) e graduandos de iniciação científica (IC) dos trabalhos da DQM de 1993 a 2002

\begin{tabular}{rcrrr}
\hline Ano & Autores & PQ $(\%)$ & PG $(\%)$ & \multicolumn{1}{c}{ IC $(\%)$} \\
\hline 1993 & 149 & $88(59,1)$ & $40(26,8)$ & $21(14,1)$ \\
1994 & 242 & $138(57,0)$ & $71(29,3)$ & $33(13,6)$ \\
1995 & 372 & $225(60,5)$ & $93(25,0)$ & $54(14,5)$ \\
1996 & 382 & $219(57,3)$ & $85(22,3)$ & $78(20,4)$ \\
1997 & 341 & $200(58,7)$ & $84(24,6)$ & $57(16,7)$ \\
1998 & 447 & $278(62,2)$ & $117(26,2)$ & $52(11,6)$ \\
1999 & 469 & $295(62,9)$ & $106(22,6)$ & $68(14,5)$ \\
2000 & 536 & $331(61,8)$ & $121(22,6)$ & $84(15,7)$ \\
2001 & 481 & $298(62,0)$ & $120(24,9)$ & $63(13,1)$ \\
2002 & 763 & $457(59,9)$ & $179(23,5)$ & $127(16,6)$ \\
\hline
\end{tabular}

Tabela 7. Número de trabalhos e afiliação institucional das apresentações na DQM desde 1993 a 2002 para a visualização das relações de cooperação científica e inter-institucional. Os valores entre parênteses referem-se à porcentagem correspondente

\begin{tabular}{|c|c|c|c|c|c|}
\hline $\begin{array}{l}\text { ANO } \\
\text { Reunião Anual }\end{array}$ & $\begin{array}{c}1993 \\
\text { 16a.RA }\end{array}$ & $\begin{array}{c}1994 \\
\text { 17a.RA }\end{array}$ & $\begin{array}{c}1995 \\
\text { 18a.RA }\end{array}$ & $\begin{array}{c}1996 \\
\text { 19a.RA }\end{array}$ & $\begin{array}{c}1997 \\
20 \mathrm{a} . \mathrm{RA}\end{array}$ \\
\hline no.trabalhos / (\%) & $48 /(100)$ & $84 /(100)$ & $115 /(100)$ & $116 /(100)$ & $96 /(100)$ \\
\hline no.trabalhos de 1 instituição / (\%) & $40 /(83,3)$ & $66 /(78,6)$ & $76 /(66,1)$ & $85 /(73,3)$ & $65 /(67,7)$ \\
\hline no.trabalhos de 2 instituições / (\%) & $08 /(16,7)$ & $16 /(19,0)$ & $31 /(27,0)$ & $24 /(20,7)$ & $25 /(26,0)$ \\
\hline no.trabalhos de 3 instituições / (\%) & $-/(0,0)$ & $02 /(2,4)$ & $07 /(6,1)$ & $05 /(4,3)$ & $06 /(6,3)$ \\
\hline no.trabalhos de 4 instituições / (\%) & $-/(0,0)$ & $-/(0,0)$ & $01 /(0,9)$ & $02 /(1,7)$ & $-/(0,0)$ \\
\hline no.trabalhos de 5 instituições / (\%) & $-/(0,0)$ & $-/(0,0)$ & $-/(0,0)$ & $-/(0,0)$ & $-/(0,0)$ \\
\hline no.trabalhos de 1 instituição e mais de 1 departamento / (\%) & $02 /(4,2)$ & $04 /(4,8)$ & $07 /(6,1)$ & $14 /(12,1)$ & $16 /(16,7)$ \\
\hline ANO & 1998 & 1999 & 2000 & 2001 & 2002 \\
\hline Reunião Anual & 21a.RA & 22a.RA & 23a.RA & 24a.RA & 25a.RA \\
\hline no.trabalhos / (\%) & $131 /(100)$ & $133 /(100)$ & $164 /(100)$ & $143 /(100)$ & $196 /(100)$ \\
\hline no.trabalhos de 1 instituição / (\%) & $87 /(66,0)$ & $86 /(64,7)$ & $113 /(68,9)$ & $102 /(71,3)$ & $122 /(62,2)$ \\
\hline no.trabalhos de 2 instituições / (\%) & $32 /(24,4)$ & $37 /(27,8)$ & $40 /(24,4)$ & $37 /(25,9)$ & $60 /(30,6)$ \\
\hline no.trabalhos de 3 instituições / (\%) & $11 /(8,4)$ & $10 /(7,5)$ & $10 /(6,1)$ & $01 /(0,7)$ & $13 /(6,6)$ \\
\hline no.trabalhos de 4 instituições / (\%) & $01 /(0,8)$ & $-/(0,0)$ & $-/(0,0)$ & $03 /(2,1)$ & $01 /(0,5)$ \\
\hline no.trabalhos de 1 instituição e mais de 1 departamento / (\%) & $15 /(11,5)$ & $11 /(8,3)$ & $09 /(6,0)$ & $10 /(7,0)$ & $15 /(7,7)$ \\
\hline
\end{tabular}


Os trabalhos realizados em duas instituições aumentaram de $16 \%$ em 1993 a 30,6\% em 2002, sendo que em média o valor de $25 \%$ refere-se a trabalhos de colaboração entre duas instituições. A colaboração entre pesquisadores do mesmo estado é de 15\%. Este resultado foi atribuído ${ }^{1}$ a: i) isolamento dos diferentes grupos dentro do próprio estado ou região, e ii) políticas e recursos disponibilizados não estão sendo suficientes para permitir a formação de redes ou sistemas estaduais de pesquisa em Química de Materiais. É evidente que estas observações somente se aplicam a aqueles estados nos quais existem várias instituições desenvolvendo atividades na área (São Paulo, Rio de Janeiro, Minas Gerais). Cabe ressaltar outra observação em relação à baixa ocorrência de colaboração inter-estados (10\%), evidenciando que os centros mais desenvolvidos, apesar de formarem grande parte dos recursos humanos, não estão sendo capazes de consolidar laços importantes de pesquisa com grupos emergentes regionais, ou com novas lideranças formadas em seu próprio meio, que exercem atividades em outros estados ${ }^{1}$.

A cooperação internacional com grupos de pesquisa no exterior ainda é muito acanhada, menor que 5\%, aparecendo na autoria dos trabalhos apresentados na DQM. Os esforços para a cooperação científica internacional parecem mais restritos na área de Química de Materiais.

\section{Características que requerem atenção}

Predominam as abordagens experimentais, e a sua associação a modelos teóricos e a trabalhos de modelagem ou simulação é pouco frequiente. Um dos principais saltos de qualidade nesta área poderá ocorrer exatamente em decorrência de uma associação mais forte, entre pesquisadores experimentais teóricos ou computacionais.

Uma importante limitação da atividade na Química de Materiais é a pouca freqüência de menção, por parte dos pesquisadores, à literatura de patentes. Isto revela uma situação preocupante, com o risco de criar dois tipos de conseqüências negativas:

i) A falta de consideração das patentes registradas nos bancos de dados internacionais prejudica o domínio do estado da arte por parte dos pesquisadores, porque os documentos de patentes contêm informação científica que, com grande freqüência, não chega à literatura aberta. Estimativas a respeito indicam que a metade das descobertas científicas relatadas em patentes jamais é objeto de publicação.

ii) Descobertas patenteáveis são um importante elemento do processo de inovação, e as patentes podem contribuir muito para a interação entre pesquisadores de universidades e empresas. De fato, em muitos casos a existência de patente é um elemento essencial nas discussões e acordos entre institutições acadêmicas e empresas.

Outro aspecto que já foi apontado em trabalho anterior ${ }^{1}$ diz respeito à carência de aprofundamento que se observa quando do uso da maioria das técnicas de caracterização, sobretudo as espectroscópicas. Não temos dúvida de que a Química de Materiais está fortemente alicerçada nos conhecimentos da Físico Química moderna. Assim, sendo Químicos e estudando materiais devemos utilizar todo o arcabouço teórico e experimental que a Química disponibiliza no seu estado-da-arte, sob pena de caminharmos na direção de uma perda de identidade.

\section{CONCLUSÕES}

A área de Química de Materiais é muito dinâmica e tem uma produção científica elevada e rapidamente crescente, com boa inserção internacional. Ela tem uma boa capacidade de atração de estudantes, formando-se uma comunidade jovem que requer recursos substanciais para poder contribuir científica e tecnologicamente.

$\mathrm{O}$ aumento do intercâmbio nacional e internacional, visando uma melhor distribuição do conhecimento e o compartilhamento de facilidades laboratoriais e bibliográficas, contribuirá para a contínua elevação do nível das pesquisas e para a formação de quadros que mantenham as atuais características positivas da área, superando as deficiências que também são percebidas.

\section{REFERÊNCIAS}

1. Alves, O. L.; Quim. Nova 1998, 21, 807.

2. http://lques.iq.unicamp.br/institucional/o laboratorio/olaboratorio.html, acessada em Maio 2002

3. Galembeck, F.; comunicação pessoal: apresentação em mesa-redonda no $4^{\text {th }}$ International Meeting on Polymer Science and Technology, La Plata, Argentina, 1982.

4. http://www.cnpq.br/plataformalattes/dgp/versao4/busca_textual/index.html, acessada em Maio 2002

5. Galembeck, F. Em Chemical Sciences em Science in Brazil; Bevilacqua, L., ed.; Academia Brasileira de Ciências: Rio de Janeiro, 1999, p. 19.

\section{APÊNDICE}

\section{DIVISÃO DE QUÍMICA DE MATERIAIS}

\author{
Número de filiados: 223 (atual)
}

2000-2002

DIRETOR:

VICE-DIRETOR:

TESOUREIRO:

Miguel Jafellici Jr.

Adley Forti Rubira

Aldo José M. Zarbin

1998-2000

DIRETOR:

VICE-DIRETOR:

TESOUREIRO:

Miguel Jafelicci Jr.

Adley Forti Rubira

Celso Aparecido Bertran

1996-1998

DIRETOR:

VICE-DIRETOR:

Oswaldo Luiz Alves

TESOUREIRO:

Fred Fujiwara

Miguel Jafelicci Jr.

1994-1996

DIRETOR:

VICE-DIRETOR:

Oswaldo Luiz Alves

Marco A. Araujo

TESOUREIRO:
Tereza Dib Zambon Atvars 